\title{
A Case Diagnosed as Bronchial Asthma Revealing a Diverticulum of Kommerell with an Abberant Right Subclavian Artery
}

\author{
Tsuyoshi Nozue, Natsuko Mori and Ichiro Michishita
}

Key words: diverticulum of Kommerell, aberrant right subclavian artery, vascular ring

(DOI: 10.2169/internalmedicine.45.1726)

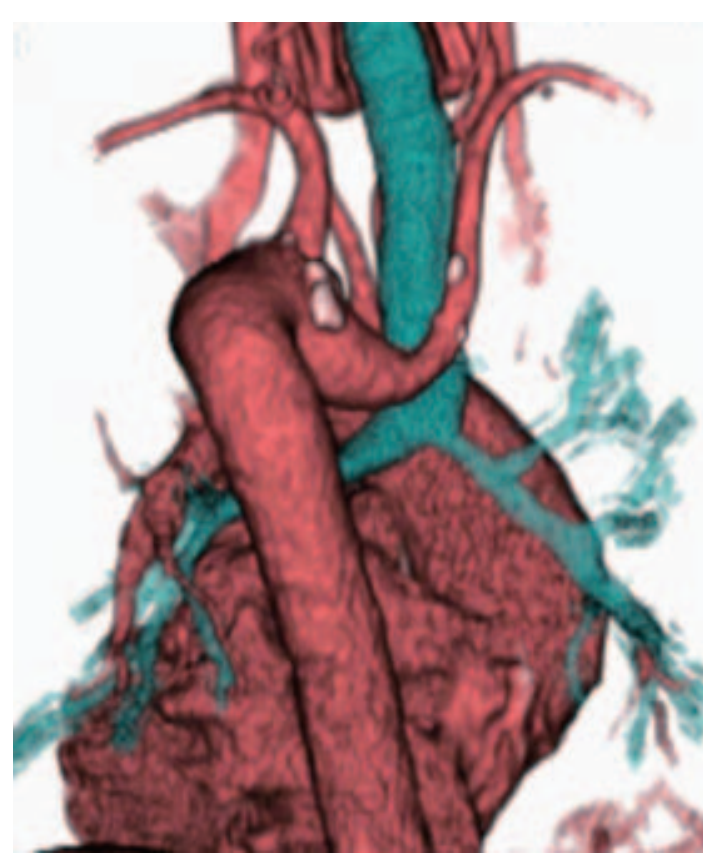

Figure 1. Three-dimensional computed tomographic scans (P-A view) showed the left aortic arch with an aberrant right subclavian artery arising from the diverticulum of Kommerell.

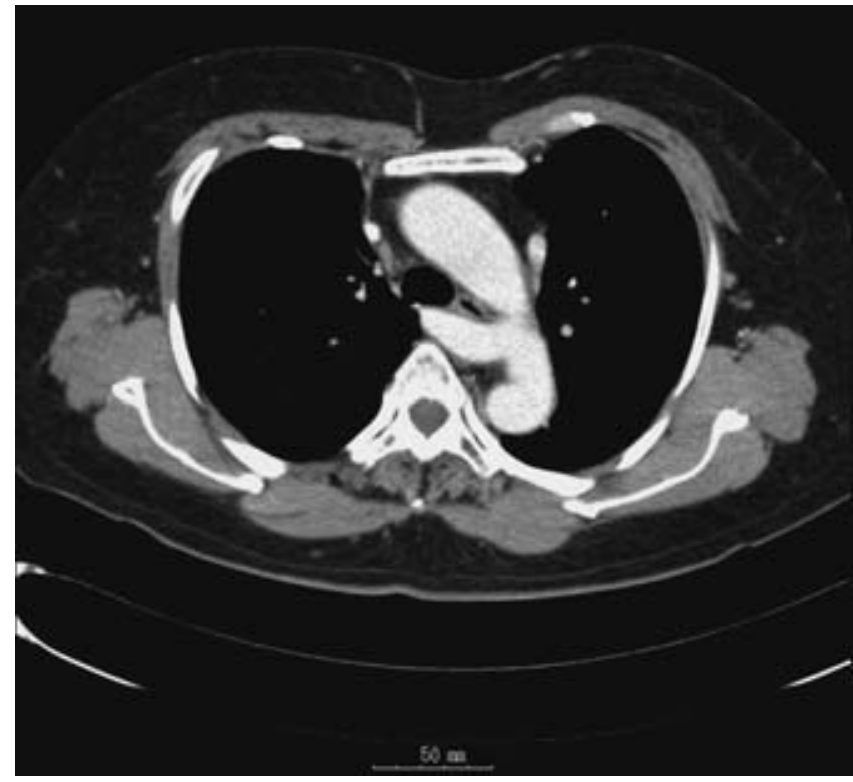

Figure 2. Two-dimensional computed tomographic scans revealed that both the trachea and esophagus were compressed by this vascular ring.

A 67-year-old woman who was diagnosed as bronchial asthma from her clinical symptoms such as dyspnea and cough admitted to our hospital complained of worsening dyspnea and dysphagia on June 7, 2005. The three-dimensional computed tomographic scans (Fig. 1) showed the left aortic arch with an aberrant right subclavian artery arising from the diverticulum of Kommerell, and both trachea and esophagus were compressed by this vascular ring (Fig. 2). As the aortogram showed the same findings (Fig. 3), we confirmed the diagnosis that her symptoms occurred due to this vascular anomaly.

Patients who have an aberrant right subclavian artery most often remain asymptomatic, because this vascular anomaly does not always arise from a diverticulum. During adulthood, approximately 5\% of patients with an aberrant right subclavian artery experience symptoms due to the development of atherosclerotic rigidity and tortuosity, especially if the aberrant right subclavian artery originates from a diverticulum, because the trachea and esophagus are encircled by vascular structure

Division of Cardiology, Department of Internal Medicine, Yokohama Sakae Kyosai Hospital, Yokohama

Received for publication January 10, 2006; Accepted for publication March 29, 2006

Correspondence to Tsuyoshi Nozue, Division of Cardiology, Department of Internal Medicine, Yokohama Sakae Kyosai Hospital, 132 Katsuracho, Sakae-ku, Yokohama 247-8581 
DOI: 10.2169 /internalmedicine.45.1726

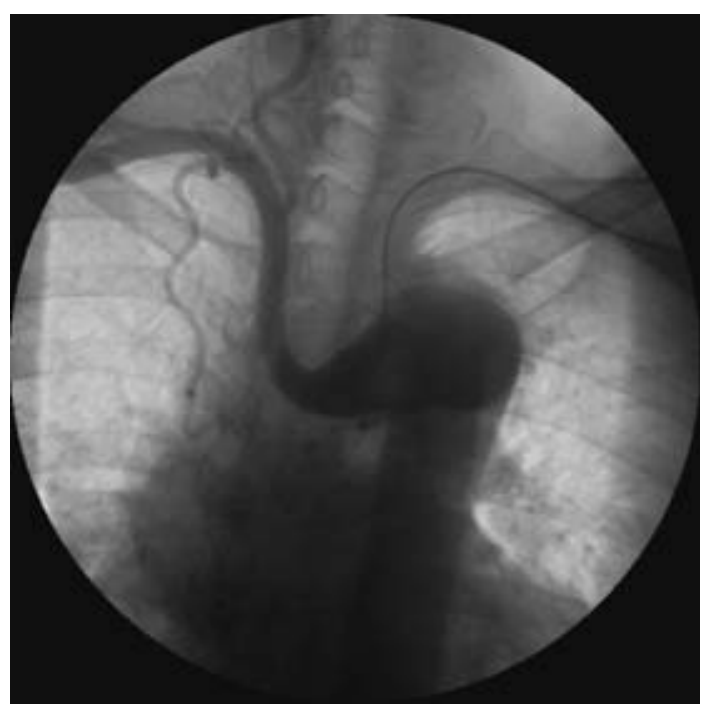

Figure 3. The aortogram (A-P view) showed the same findings as the three-dimensional computed tomographic scans.

\section{$(1,2)$.}

Therefore, it is necessary for physicians to recognize that tracheal or esophageal symptoms would be caused by such vascular anomaly.

\section{References}

1. Backer CL, Ilbawi MN, Idriss FS, DeLeon SY. Vascular anomalies causing tracheoesophageal compression. Review of experience in children. J Thorac Cardiovasc Surg 97: 725-731, 1989.

2. van Son JA, Julsrud PR, Hagler DJ, et al. Surgical treatment of vascular rings: the Mayo Clinic experience. Mayo Clin Proc 68: 1056-1063, 1993.

(C) 2006 The Japanese Society of Internal Medicine http://www.naika.or.jp/imindex.html 